Artigo recebido em:

21.02.2019

Aprovado em:

30.03.2019

Fernanda Maurício Silva

Professora do Programa de Pós-graduação em

Comunicação da Universidade Federal de Minas

Gerais. Doutora em

Comunicação e Cultura

Contemporânea pela

Universidade Federal da

Bahia.

E-mail: fernandamauricio@gmail.com
Estudos em Jornalismo e Mídia Vol. 16 No 1 Janeiro a Junho de 2019 ISSNe 1984-6924

\section{Criticando a TV: considerações sobre o papel da crítica na construção dos gêneros televisivos}

Fernanda Maurício Silva

\section{Resumo}

O presente artigo tem como objetivo discutir a produtividade da crítica especializada para a construção dos gêneros televisivos e sua historicidade tomando como principal referência as contribuições dos estudos culturais para análise da televisão. Tendo como objeto empírico o programa Fantástico: show da vida (TV Globo), o artigo analisa as críticas publicadas em jornais e revistas nacionais ao longo de suas três primeiras décadas buscando mostrar as práticas discursivas de definição, interpretação e avaliação do programa, bem como as especificidades da crítica desse programa.

Palavras-chave: Crítica. Historicidade da televisão. Gêneros televisivos. Fantástico.

Criticizing TV: considerations about the role of criticism in the construction of television genres

\begin{abstract}
This article aims to discuss the productivity of specialized critics for the construction of television genres and their historicity, taking as their main reference the contributions of cultural studies for television analysis. Having as an empirical object the program Fantastic: show of life (TV Globo), the article analyzes the criticisms published in national newspapers and magazines throughout its first three decades seeking to show the discursive practices of definition, interpretation and evaluation of the program, as well as the specifics of the critique of this program.
\end{abstract}

Key words: Criticismo. Historicity of television. Television genres. Fantástico. 
$s$ análises de produtos televisivos no Brasil, especialmente os jornalísticos, têm como eixo central a produção no presente. A historicidade dos gêneros televisivos, conquanto esteja em crescimento no país, tem se esbarrado na dificuldade de acesso aos acervos do audiovisual. Para suprir as lacunas, os pesquisadores muitas vezes recorrem a fontes amadoras, produtos incompletos e editados (SILVA, GUTMANN, 2015). Como consequência, a construção da memória televisiva e cultural do país torna-se fragmentada, entremeada por recortes do passado.

A fim de dar conta das lacunas na historiografia televisiva brasileira, os pesquisadores recorrem aos textos impressos dos programas, scripts disponíveis ou ainda à crítica especializada disponibilizada por jornais impressos e revistas. Segundo João Freire Filho (2008), embora a ausência de acervo imponha dificuldades na pesquisa histórica sobre a televisão, a ampliação da noção de "análise textual" permite ao pesquisador levantar esse "entorno textual" que contribui para a composição das etapas dessa história (FREIRE FILHO, 2008, p. 129).

O presente artigo parte do pressuposto de que para além de fornecer uma fonte alternativa de pesquisa de gêneros televisivos, a crítica especializada (assim com a constituída pelos telespectadores) os configura, tornando-se um espaço privilegiado de circulação de sentidos acerca dos gêneros e produtos da TV. Recorrentemente os textos críticos oferecem não apenas os juízos de valor acerca do televisivo, como revela, principalmente, o tensionamento da própria formação dos gêneros, as disputas discursivas em torno deles e de seu processo de legitimação.

Ancorando-se nos pressupostos dos estudos culturais para análise da televisão, o presente artigo tem como objetivo evidenciar de que modo a crítica especializada contribui para a configuração de gêneros televisivos a partir de uma visada histórica. Para tanto, selecionamos o gênero revista eletrônica a partir de seu produto mais longevo, o programa Fantástico: show da Vida, exibido aos domingos pela TV Globo há mais de quarenta anos. As críticas sobre o programa, em sua estreia, ressaltam o caráter inovador e os ganhos da aliança entre informação e entretenimento, num momento em que essa fórmula se apresentava como uma novidade. No entanto, tal configuração se apresentava também como um problema de identidade e pertencimento do gênero nas categorias pré-estabelecidas. Este artigo efetua uma breve análise do Fantástico a partir da crítica televisiva, buscando identificar as práticas discursivas de definição, avaliação e interpretação (MITTELL, 2004) disponíveis e disputadas em suas três primeiras décadas de existência ${ }^{1}$. As questões que nortearam este exercício são: de que forma o Fantástico tensiona as convenções do gênero telejornalismo? O que ele nos diz das convenções televisivas? De que modo os textos críticos que circulam na mídia nos fazem ver as marcas desse tensionamento? Como eles contribuem para estabelecer ou romper com as convenções? Que valores carrega para acrescentar ao telejornalismo enquanto gênero?

\section{A historicidade dos gêneros televisivos}

As contribuições dos estudos culturais para análise dos gêneros televisivos têm ganhado cada vez mais espaço da bibliografia do país (GOMES, 2011a; GUTMANN, 2014; SILVA, 2012; GUTMANN; SILVA, 2015). Essas pesquisas assumem a noção de gênero televisivo como um operador metodológico produtivo por evidenciar as disputas e tensionamentos provocados nos produtos televisivos, seja nas produções mais contemporâneas, seja nas históricas. Segundo Jason Mittell (2004), toda análise de gênero televisivo envolve uma dimensão histórica, independentemente do recorte temporal realizado. Rechaçando uma noção de gênero como uma simples classificação dos produtos em categorias fixas, Mittell afirma que uma análise cultural dos gêneros televisivos envolve o investimento em uma genealogia, conforme proposta por Michel Foucault (2010), privilegiando uma larga coleta de discursos que circulam sobre o gênero, ao invés de se traduzir em
${ }^{1}$ Este artigo é produzido como resultado de pesquisa financiada pelo CNPq. 
${ }^{2} \mathrm{O}$ próprio Jason Mittell (2001) possui uma interessante análise sobre como os videoclipes Beat it, Thriller $e$ Bad, de Michael Jackson, desafiaram a noção dominante e institucionalizada do que era um videoclipe estabelecida pela MTV no início dos anos 1980.

A emissora negava-se a exibir o trio de clipes do artista alegando que não se tratava de vídeo clipe uma vez que continham uma pequena história ficcional, com diálogos e encenações. Mittell demonstra que uma disputa institucional se deu

entre emissora, artistas, críticos e órgãos reguladores da TV norte-americana de modo a alargar a noção de videoclipe para incorporar outros produtos.

${ }^{3} J a s o n$ Mittell está interessado particularmente no modo como a audiência efetua um processo de avaliação dos produtos televisivos. Trataremos de como a crítica participa das práticas de avaliação mais adiante. macro-estruturas e cronologias. Para Mittell, as convenções se formam em meio a disputas de sentidos e discursos que se flagram fora dos textos televisivos.

A história do gênero contribui com a formação de sua definição, seus significados e valores sociais: "não apenas a historiografia dos gêneros ajuda a definer sua composição particular, como também oferece uma visão particular daquilo que os gêneros são" (MITTELL, 2004, p. 30). Isso significa que para compreendermos os gêneros televisivos e como eles se desenvolvem no presente, suas convenções e marcas dominantes, é necessário compreender as matrizes históricas e culturais que configuraram sua estrutura, as transformações efetuadas não apenas nos textos, mas em todo um circuito cultural que envolve sua produção. Para isso, Mittell irá se aproximar do conceito de genealogia discursiva de Foucault, que mapeia

As regularidades e descontinuidades discursivas constitutivas de qualquer gênero, enlaçando essas práticas a relações de poder contextuais e regimes discursivos mais amplos, pois o objeto da historiografia genérica torna-se a ampla variedade de práticas discursivas constituindo uma categoria cultural em qualquer momento histórico ou de mudança. (MITTELL, 2004, p. 30)

Para Mittell, existem três práticas discursivas que contribuem para a análise dos gêneros e que operam de forma concomitante. As práticas de definição se ancoram na identidade do gênero e no reconhecimento que produção e recepção partilham (ou não) acerca de suas convenções. As práticas de definição põem em contato a identificação de marcas textuais e o circuito cultural que estabelece aquelas que irão se configurar como dominantes e atuar na classificação do gênero, o que pode ocorrer por meio de disputas discursivas, uma vez que, por vezes, os produtos desafiam os limites convencionados de certos gêneros ${ }^{2}$.

Mittell denomina práticas discursivas de interpretação aquelas que, por sua vez, dizem respeito à localização de valores sociais reproduzidos nos e pelos gêneros. O modo como questões raciais, de classe, homoafetivas, etc, transitam pelos produtos televisivos e sua aceitação (ou não) pela sociedade envolvem o reconhecimento de que valores estão em operação nos produtos e os que são silenciados.

As práticas de avaliação envolvem a atribuição (ou não) de qualidade aos produtos televisivos, destacando os critérios a partir dos quais esse julgamento é efetuado. Seja por parte dos críticos, sejam os telespectadores, os produtos televisivos estão em permanente processo de avaliação. Para o autor, a avaliação dos gêneros é uma maneira de afirmação de identidade e de se localizar na hierarquia social. Segundo ele, as práticas de avaliação "parecem ser uma questão crucial para a audiência, uma vez que as hierarquias entre os programas e gêneros são um dos primeiros meios pelos quais os telespectadores situam-se na relação com os textos midiáticos e sua localização social” (MITTELL, 2004, p. 101). O gosto, para o autor, não é apenas algo partilhado esteticamente (como se estivesse presente na obra), mas é construído socialmente através de forças históricas. Assim, para Mittell, afirmar que um programa é "bom" significa dizer de seu pertencimento social e de como os telespectadores criam as regras e convenções por meio das quais as obras devem ser avaliadas a fim de legitimar seus próprios prazeres e afetos ${ }^{3}$.

Essas práticas são constitutivas do gênero, fazem parte dele, mas não são exclusivas dos textos audiovisuais. Embora os discursos possam revelar aspectos diferentes do conjunto de material coletado pode surgir a regularidade. Por isso, o importante não é encontrar as definições, interpretações e avaliações corretas ou mais apropriadas, mas "explorar o modo como os gêneros são culturalmente definidos, interpretados e avaliados em suas formas materiais" (MITTELL, 2004, p. 9). Sendo assim, Mittell defende que é pela análise de um contexto específico que se chega aos aspectos mais amplos. Para ele, a historicidade dos gêneros televisivos é um processo fluido que não se baseia apenas na emergência e declínio de um programa, mas na história das definições, interpretações e avaliações que circulam sobre os gêneros, como essas práticas discursivas se articulam (ou não) com a categoria e como se relacionam com várias esferas do contexto industrial, da audiência, da crítica, das instituições. Por isso mesmo é 
que, para Mittell, a questão dos documentos é fundamental, uma vez que as práticas discursivas estão dispersas em diversos espaços: coberturas da grande imprensa e da imprensa alternativa, críticas, materiais promocionais e outras representações e produtos (merchandising, paródias etc), documentos pessoais e corporativos, manuais de produção, materiais governamentais, audiência e histórias orais. Neste artigo, iremos nos ater às críticas publicadas entre as décadas de 1970 e 1990 sobre o programa Fantástico, a fim de discutirmos o papel da crítica na constituição do gênero a que hoje o programa se enquadra: a revista eletrônica.

A crítica especializada participa ativamente da construção dos gêneros de modo a fazer circular os sentidos sociais que definem os gêneros selecionando certas marcas que funcionam como convenções e silenciando outras (SILVA, 2016). Também a crítica, como temos visto em muitos trabalhos, diz da sociedade, das condições contextuais que atuam sobre os produtos que autenticam sua legitimidade ou não. De igual modo, a crítica efetua uma valoração de bom/mau (programa, apresentador, gênero, emissora etc). Embora esses quadros valorativos, muitas vezes, sejam tomados como normativos, eles são flexíveis, moldados não apenas pelo contexto institucional de cada crítico, mas principalmente pelas condições que enquadram os produtos televisivos.

Embora exerça igualmente as três práticas discursivas, destaca-se o processo de avaliação como trabalho especializado do crítico. $\mathrm{O}$ relevo aos aspectos que qualificam um programa como bom/mau apresentam-se, em nossa análise, como os elementos centrais dos textos críticos que ora focam no conteúdo do programa, ora em seus aspectos formais. Percebemos que há um horizonte de qualidade que permeia e orienta os textos críticos e que discutiremos na análise. Entretanto, vale considerar que a noção de qualidade, quando tomada como marca textual de valor, acaba perdendo os critérios avaliativos e o valor do programa passa a estar contido apenas no texto, deixando de lado o contexto e o engajamento ativo do telespectador.

Detalhando um pouco mais o processo de avaliação, Mittell efetua uma diferenciação entre validação - o processo de medição de valor que está contido nos textos esperando para que o crítico o revele a partir de critérios universais - e o de avaliação, "o processo ativo de engajamento com critérios estéticos, gestos textuais e circulação cultural.” (MITTELL, 2015, p. 215). Deste modo, enquanto a validação presume que o crítico, a partir de um processo de apreciação, irá revelar a verdade, a avaliação enfatiza o processo cultural do consumo no qual significado e valor são produzidos. Deste modo, para Mittell, nem a qualidade está contida nos textos, nem é papel do crítico revela-la, mas antes demonstrar de que forma o produto opera a fim de alcançar seus objetivos. O autor propõe que o processo de avaliação não deve focar apenas nos produtos, mas em como ele empreende uma vinculação com o contexto e os regimes de verdade que lhes dá sustentação.

Encontramos em Raymond Williams (2011) outra contribuição para entendermos como a crítica cultural é capaz de unir uma leitura profícua dos textos numa relação estreita com contexto. Contrário à afirmação de critérios universais para julgamento dos produtos culturais, Williams afirma que o que problematiza essa avaliação são os critérios adotados como balizas:

Certos romances são 'obras de arte', mas outros são 'sensacionalistas', 'lixo comercial', 'subliteratura' ou 'paraliteratura', e ainda outros, entre esses dois extremos, são 'repetitivos', 'mediocres' ou 'recheio de bibliotecas circulantes'. Todos nós podemos nos lembrar de exemplos a que aplicaríamos essas descrições e estaríamos dispostos a justifica-las. Os termos são ainda mais duros nas artes mais populares, mas a tendência existe em relação a todas elas. (WILLIAMS, 2011, p. 124).

Crítico literário, Williams assume que toda crítica provoca tensionamentos e disputas pelos limites de determinadas categorias. A questão central para o autor, porém, são os critérios através dos quais isto é feito. Segundo ele, as distinções entre arte e não-arte podem ser vistas como 
formas sociais variáveis no interior das quais as práticas relevantes são percebidas e organizadas. Assim, as distinções não são verdades eternas, ou categorias supra-históricas, mas elementos concretos de um tipo de organização social. (Williams, 2011, p. 129)

${ }^{4}$ Foram coletadas ao todo vinte e oito críticas publicadas nos jornais O Globo, Jornal do Brasil, Estado de S. Paulo, Folha de S. Paulo, Jornal de Brasília, O Dia $e$ na revista Veja.

Deste modo, a crítica implica identificar as marcas dominantes, as convenções que operam em determinados textos e colocá-las em contexto. A obra, portanto, não opera isolada, mas atua num diálogo com demais obras, além de todo o ambiente cultural, social, político, tecnológico, econômico em seu entorno. O gênero, para ele, traz um conjunto de convenções mais amplas que incidem sobre a obra. Nós reconhecemos o texto "devido a certas características dominantes, vinculando-o então a uma categoria maior, o gênero; podemos então encontrar os componentes do gênero em uma história social específica" (WILLIAMS, 2011, p. 67).

Tendo em vista esses parâmetros, partimos para a análise das críticas publicadas em jornais e revistas brasileiros sobre o programa Fantástico em suas três primeiras décadas. O material disponível é amplo e foi necessário um recorte realizado nos anos de 1973 (estreia do programa), 1974, 1984 e 19944. O foco da análise foi nas práticas discursivas de avaliação, interpretação e definição, levando-se em conta que o Fantástico foi considerado o primeiro programa a unir informação e entretenimento de modo a formar um novo gênero, que hoje convencionou-se chamar de revista eletrônica.

\section{Quando a vida é um show: parâmetros da crítica sobre o Fantástico}

Em agosto de 1973, a TV Globo estreou o programa Fantástico: o show da vida. Num contexto em que a televisão buscava construir uma linguagem própria e inovar em produções consideradas de maior qualidade, Fantástico surgiu na grade de programação como uma promessa de elevar a programação dos domingos, que era dominada por programas de auditório. A proposta, desde o início até hoje, era conciliar jornalismo e entretenimento por meio de uma fórmula que se baseava, em especial, no forte aparato tecnológico da emissora para produção de seus programas. Buscando implementar algum tipo de transformação, Fantástico afirmou-se como um produto contrário a modismos, como evidenciou o produtor Luiz Lobo: "a programação da TV sempre foi baseada em modismos [...] Só uma coisa não muda na TV: jornalismo. Por isso, um programa que alie a informação à diversão certamente é o único que pode sobreviver bastante tempo" (RITO, 15 ago. 1973).

Recuperando as primeiras críticas, na ocasião da estreia e em seu primeiro ano de existência, os críticos realçam o potencial inovador da linguagem do programa. O discurso de modernização do país fomentado pelos militares encontra forte ancoragem na produção desse programa, uma vez que o "cenário futurista", o rigor no uso de imagem e som, o tempo dado aos temas, a vinheta tecnológica eram elementos constantemente destacados nas avaliações do programa como fator que lhe agregava qualidade.

Com uma definição imprecisa, o programa era classificado ora como variedades, ora como revista semanal, ora como jornal dominical, sem muita preocupação com uma fixação precisa. A ausência de concorrentes semelhantes no mesmo período e a proposta de uma hibridização entre os gêneros conhecidos borravam as expectativas dos críticos em estabelecer fronteiras rígidas para o programa. Como, segundo Mittell (2004), um programa apenas não forma um gênero, os críticos encontraram equivalentes nas produções disponíveis no mesmo período. Assim, boa parte das críticas procurava situar o programa numa relação de concorrência com os das outras emissoras. A comparação com o Programa Flávio Cavalcante (TV Tupi), animador de auditório conhecido pelo tom sensacionalista de seu programa, por exemplo, nas críticas de Valério de Andrade é recorrente.

Num contexto em que a programação dominical era quase inteiramente voltada para programas de auditório, a proposta do Fantástico de levar informação e entretenimento combinados no mesmo programa representava, nas pala- 
vras dos críticos, um "alívio”. Há, portanto, por parte da crítica, a tentativa de hierarquizar padrões de gosto e qualidade. Por isso, as marcas destacadas positivamente evidenciavam uma disputa em torno da grade de programação e da nomenclatura que designava o programa: variedades. O modo como os críticos efetuavam essa hierarquização em relação aos programas de auditório demonstravam a expectativa por uma redução do papel dos apresentadores. A posição de dois importantes críticos de TV do período, Valério de Andrade e Arthur da Távola, demonstram tal demanda:

\begin{abstract}
a Globo, inspirada na fórmula da revista ilustrada, optou por um programa que não estivesse subordinado ao estrelismo ou aos caprichos de um animador. E, o que é mais importante, conseguiu romper com a velha estrutura de palco-auditório, passando a produzir um programa de televisão e não a mera extensão da programação consagrada pela Rádio Nacional. [...] a grande atração do Fantástico repousa no que acontece no mundo e não no que se pode fazer ou trazer ao palco (ANDRADE, 07 ago. 1974).

Após vigorar nas décadas de 50 e 60, a televisão de pessoas, que centralizava na figura do animador todos os ritmos e acidentes do programa, começa a ceder lugar a formas mais ágeis e representativas do estágio técnico-humano - a que a comunicação eletrônica chegou (TÁVOLA, 06 ago. 1974).
\end{abstract}

Ambos apresentam a centralidade do apresentador como um traço que precisava ser superado para que a TV alcançasse novos parâmetros de qualidade de sua programação, e o Fantástico representava esse momento pretendido.

Nota-se, portanto, que nesse primeiro momento, há uma valorização do Fantástico em relação ao televisivo, mas ressaltando as convenções do telejornalismo reconhecidas até então - notícias sérias, grandes reportagens. Daí, também a comparação com outros programas jornalísticos consagrados no período, como Globo Repórter (Távola, 06 ago. 1974), embora pouco se tenha falado sobre a cobertura jornalística do programa nos dois primeiros anos, assim como o papel dos jornalistas. A proposta de unir informação e entretenimento acabou conduzindo os comentários dos críticos que, de um modo geral, voltaram-se para a estrutura do programa. É possível, porém, depreender alguns sentidos vistos como positivos a respeito do jornalismo praticado pelo programa. Para Valério de Andrade, Fantástico equilibrava um jornalismo mais aprofundado ("completando o que os jornais divulgaram pela manhã") com o imediatismo que a televisão permitia naquele período ("antecipando o que vai ser divulgado na segunda-feira") (ANDRADE, 07 ago. 1974). Távola, por sua vez, via com bons olhos a aliança entre jornalismo e ficção: "Fantástico também acerta em cheio, refazendo, recriando fantasia e realidade, as duas mais misturadas evidências do mundo contemporâneo" (TÁVOLA, 06 ago. 1974).

Dez anos após sua estreia, a tônica do programa voltou-se mais para o jornalismo. Mauricio Scherman, diretor geral do programa na ocasião, afirmou:

Minha visão do Fantástico era a de um homem vindo do teatro, que passou pelo show e pelo jornalismo. Hoje, o programa tem um forte enfoque jornalístico; se antes ele era entretenimento mais informação, hoje é informação mais entretenimento" (BAPTISTA, 07 ago. 1983).

As práticas jornalísticas, no entanto, ganhavam outros contornos, substituindo as grandes reportagens com aprofundamento dos temas pelas notícias amenas e fait-divers. O investimento do programa no jornalismo se deu ainda no final dos anos 1970, quando a emissora optou pelo investimento em informação para suprir uma lacuna deixada pela ausência de programas noticiosos aos domingos. Sobre isso, o crítico Pedro Aguiar, do Jornal de Brasília, ressalta duas marcas do jornalismo que fizeram falta na repaginação do programa: a pouca ênfase no factual e as grandes reportagens policiais que, segundo ele, "estão freqüentemente a dois centímetros do "mundo cão" ou da absoluta debilidade mental” (AGUIAR, 28 jan. 1983).

O cenário televisivo nacional sofreu uma importante alteração durante os anos 1980 que parece influenciar nas escolhas efetivadas pelo programa. Duas novas 
emissoras - Manchete e SBT - surgiram no início da década reconfigurando as grades de programações e as expectativas da audiência. Enquanto a Manchete investiu em jornalismo e em produtos considerados de qualidade, o SBT popularizou a linguagem televisiva, o que levou a uma transformação nos programas. Atrelado às transformações na política (com o processo de redemocratização) e na sociedade (com a chegada da classe $\mathrm{C}$ ), o novo cenário nacional criou condições para que o Fantástico alterasse o tom e o conteúdo, mantendo a forma já conhecida da audiência: a mistura entre música, informação, ficção, humor. Por isso, em boa parte da crítica aos dez anos do programa prevalecem avaliações contrárias à repetição da fórmula já consagrada e ao sensacionalismo da cobertura jornalística.

Maria Helena Dutra, crítica de TV do Jornal do Brasil, apresenta pouco entusiasmo ao tratar da fórmula do programa: ainda que elástica, mostrava sinais de desgaste. O sensacionalismo como qualificativo negativo do programa apareceu em diversas ocasiões, não apenas nas reportagens policiais, mas nas de temática científica que tratavam da cura de doenças. Para além de pontuar as falhas do programa, Dutra demanda um jornalismo mais engajado tendo em vista a liberdade com relação à censura:

Quando não se pode escapar de respingar alguma autoridade, terceiro escalão do governo ou qualquer entidade ou associação do mundo livre, fabrica-se rapidamente um editorial restabelecendo a lei e a ordem (DUTRA, 07 ago. 1983).

Do ponto de vista das práticas discursivas de definição, a nomenclatura "revista" passou a ser mais empregada para definir o programa, o que reduziu as disputas em torno de sua identidade e seu reconhecimento durante os anos 1980. Na maior parte dos casos, quando efetuavam comparações, os críticos usavam o próprio programa como parâmetro, buscando poucas referências externas. Deste modo, as críticas tornavam-se um pouco menos contextuais do ponto de vista midiático, mas abordavam um pouco mais do cenário político, econômico e cultural do período.

Se nos anos 1980 o Fantástico iniciou um processo de forte investimento no jornalismo ameno, nos primeiros anos da década de 1990 essa marca se estabeleceu na construção do programa. Luís Antônio Nascimento, diretor geral do Fantástico no período, diz que "uma das filosofias do programa será a de cada vez mais tornar as noites de domingo mais amenas para o telespectador que, no dia seguinte, tem de enfrentar um dia a dia cujas agruras já são devidamente mostradas pelos telejornais" (MÁXIMO, 08 set. 1993). Por meio de recursos visuais, o programa buscava transmitir temas sérios em tom mais informal e didático.

Por outro lado, a elasticidade da fórmula do programa possibilitou o investimento no jornalismo investigativo. Temas como "remédios inócuos, a conexão nigeriana, a água sanitária que não mata os micróbios e a boa-vida que os juízes do INSS levam na prisão" (ESQUENAZI, 17 abr. 1993) tornaram-se pauta do programa que investia cada vez mais no jornalismo. Esse investimento era notório no time de profissionais que iriam compor a bancada do programa e que cada vez mais se tornavam pauta para os críticos. Celso Freitas, Valéria Monteiro, Fátima Bernardes, Sandra Annemberg entre outros passaram pela bancada do programa constituindo uma espécie de celebrização dos jornalistas. Sobre Fátima Bernardes, a jornalista Ana Cláudia Souza, do Jornal do Brasil, destaca: "ao contrário de suas antecessoras no Fantástico, Fátima Bernardes, 30 anos, não tem passado de modelo nem pretensões à carreira artística. Talvez por isso, ouvir que é uma estrela ainda soe estranho" (SOUZA, 10 abr. 1993).

Durante esse período, é possível notar uma mudança no teor da crítica especializada: embora se mantivesse especialmente atenta à crítica aos elementos do programa, destacando possíveis falhas, a dureza da década anterior contrasta com o tom promocional efetuado por boa parte dos textos. Não se tratava de enaltecer o programa, mas de conceder mais espaço às vozes institucionais que o compunham. 
Como consequência, os textos críticos tornam-se mais resenhas do que espaços de discussão sobre o papel da televisão e seus programas, silenciando disputas discursivas em torno dos gêneros e estabelecendo convenções que deveriam se reproduzir nos programas que surgiram na década posterior.

\section{Considerações finais}

Tomar a crítica televisiva como objeto para análise histórica da TV nos permite perceber disputas e tensionamentos em torno dos gêneros, mas também a tentativa de estabelecer consensos e silenciamentos. As críticas das três primeiras décadas do Fantástico demonstram o empenho em estabelecer um "cânone" (JOHNSON, 2007), do que problematizar o programa. A complexidade do produto, com seus diversos quadros que misturavam informação e entretenimento, e as condições de produção dos críticos (de produzir textos curtos de forma rápida), apresentam-se como um entrave para maior contextualização do programa. Nem mesmo nas críticas sobre sua estreia foi possível recriar as matrizes históricas do Fantástico, que foi apresentado como algo totalmente novo na grade de programação. O que também se percebe é que enquanto o programa foi dirigindo-se para a produção de um jornalismo mais ameno e informal, a crítica foi endossando suas escolhas, de modo a dar espaço para as vozes institucionais apresentarem as novidades do programa sem tensionamento ou contextualização por parte dos textos críticos.

Do ponto de vista das práticas discursivas, os textos ainda oferecem vislumbres de disputas em torno da definição, como ocorreu nos anos 1970 com os programas de auditório, também classificados como programas de variedades, assim como o Fantástico. No processo de reprodução de marcas do gênero, porém, já nos anos 2000, é notável que a nomenclatura "revista eletrônica" estava consolidada culturalmente e o jornalismo foi selecionado como principal elemento a ser reproduzido. Do ponto de vista da avaliação, o programa desde o início se sustentou num ideal de inovação permanente que foi o principal parâmetro para sua avaliação (positiva ou negativa) empregado pelos críticos de TV.

Certamente ainda há muito a se explorar a respeito da crítica televisiva e sua contribuição para a historicidade dos gêneros. O presente estudo busca apontar um caminho de pesquisa que permita superar a ausência de material audiovisual e focar nas disputas discursivas em torno dos produtos televisivos, rechaçando uma macro história dos gêneros. A compreensão das matrizes históricas não apenas resgata a memória cultural do país, como ilumina as formas contemporâneas de engajamento com os meios de comunicação, tensionadas pelas transformações tecnológicas, discursos políticos, constrangimentos econômicos e outros fatores contextuais que dão especificidade ao modo como se vê e se critica televisão hoje.

\section{Referências}

AGUIAR, P. Programa de Plástico. Jornal de Brasília, 28 jan. 1983, disponível em http://www.tv-pesquisa.com.puc-rio.br/mostraregistro.asp?CodRegistro $=5271 \& \mathrm{~Pa}-$ geNo=1. Acesso em: 25 set. 2018.

ANDRADE, V. A vida é um show. Jornal do Brasil, 08 ago. 1973. Disponível em: Disponível em: http://www.tv-pesquisa.com.puc-rio.br/mostraregistro.asp?CodRegistro $=881 \&$ PageNo=1. Acesso em: 25 set. 2018 .

Um aniversário feliz. Jornal do Brasil, 07 ago. 1974. Disponível em: http://www.tv-pesquisa.com.puc-rio.br/mostraregistro.asp?CodRegistro $=946 \& \mathrm{~Pa}-$ geNo=1. Acesso em: 25 set. 2018 . 
BAPTISTA, M. Fantástico. Jornal do Brasil, 07 ago. 1983. Disponível em http:// www.tv-pesquisa.com.puc-rio.br/mostraregistro.asp?CodRegistro $=4807 \&$ PageNo=1. Acesso em: 25 set. 2018.

DUTRA, M.H. Data histórica pela audiência. Jornal do Brasil, 07 ago. 1983. Disponível em http://www.tv-pesquisa.com.puc-rio.br/mostraregistro.asp?CodRegistro $=4807 \&$ PageNo $=1$. Acesso em: 25 set. 2018.

ESQUENAZI, R. Fantástico se renova aos 20 anos e adota estilo leve e bem humorado. Jornal do Brasil, 14 abr. 1993. Disponível em http://www.tv-pesquisa.com.puc-rio.br/mostraregistro.asp?CodRegistro $=54630 \&$ PageNo=1, acesso 25 set. 2018.

FOUCAULT, M. A arqueologia do saber. Rio de Janeiro: Forense Universitária, 2010.

FREIRE FILHO, J. Por uma agenda de investigação da história da TV no Brasil. In: RIBERIO, A.P.; HERSCHMANN, M (Org.). Comunicação e história: interfaces e novas abordagens. Rio de Janeiro: Mauad X, Globo Universidade, 2008, pp. 127-144.

GOMES, Itania M. Gênero televisivo como categoria cultural: um lugar no centro do mapa das mediações de Jesús Martín-Barbero. Revista Famecos (Impresso), v. 18, 2011a, pp. 111-130.

GUTMANN, J. Quando ruptura é convenção: O programa Gordo a Go-Go como espaço de experiência do talk show. Contracampo (UFF). N. 31. Dez/Mar., 2014.

JOHNSON, Catherine. Negotiating value and quality in television historiography. In: WHEATLEY, Helen (Org.). Re-viewing television history: critical issues in television historiography. London: I.B. Tauris, 2007.

MAXIMO, J. Fantástico muda de cara para ficar ameno. Folha de S. Paulo, 08 set. 1993. Disponível em http://www.tv-pesquisa.com.puc-rio.br/mostraregistro.asp?CodRegistro=22819\&PageNo=2. Acesso em: 25 set. 2018.

MITTELL, Jason. Genre and Television. From Cop Shows to Cartoons in American Culture. London: Routledge, 2004.

Evaluation. In: Complex TV: the poetics of contemporary television storytelling. New York: New York University Press, 2015, pp. 206-232.

RITO, L. A fuga da rotina. Revista Veja, 15 ago. 1973, p. 76.

SILVA, F, M.; GUTMANN, J. F. .Sobre textos e paratextos: construções metodológicas para análise da história cultural do talk show no Brasil. In: CHAMBAT-HOUILLON, Marie-France; COHEN, Evelyn; GOMES, Itania Maria Mota. (Org.). Estudos de Televisão Brasil França. 1ed.Salvador: EDUFBA, 2015, v. 1, p. 72-88.

SILVA, F, M.;. Gênero televisivo e história cultural: pressupostos para uma análise do talk show. Texto apresentado no XXI Encontro da Compós, Juiz de Fora, 12 a 15 jun. 2012.

SILVA, F, M.;. Quando a crítica encontra a TV: uma abordagem cultural para a análise da crítica televisiva. Revista Famecos, Porto Alegre, v. 23, n. 2, mai/ago. 2016. 
TÁVOLA, A. Um ano Fantástico. O Globo, 08 ago. 1974. Disponível em: http:// www.tv-pesquisa.com.puc-rio.br/mostraregistro.asp?CodRegistro $=944 \& \mathrm{PageNo}=1$. Acesso em: 25 set. 2018.

WILLIAMS, R. Cultura. Rio de Janeiro: Paz e Terra, 2011. 